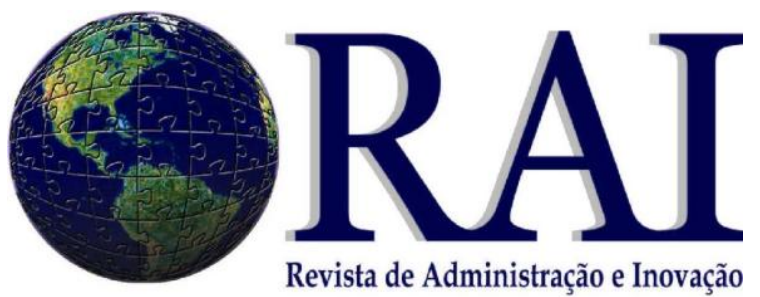

ARTIGOS

\title{
TRANSFERÊNCIA DE CONHECIMENTOS CIENTÍFICOS E TECNOLÓGICOS DA UNIVERSIDADE PARA O SEGMENTO EMPRESARIAL
}

\author{
Maurício Fernandes Pereira \\ Doutor em Engenharia de Produção pela Universidade Federal de Santa Catarina - UFSC \\ Professor adjunto 4 da Universidade Federal de Santa Catarina - UFSC \\ E-mail: mpereira@cse.ufsc.br [Brasil]
}

\section{Pedro Antônio de Melo}

Doutor em Engenharia de Produção e Sistemas pela Universidade Federal de Santa Catarina - UFSC Professor do Departamento de Ciências da Administração - CAD e do Programa de Pós-Graduação em Administração - CPGA

E-mail: pedro.inpeau@gmail.com [Brasil]

\section{Marcos Baptista Dalmau}

Doutorado em Engenharia de Produção pela Universidade Federal de Santa Catarina - UFSC

Professor adjunto da Universidade Federal de Santa Catarina- UFSC

E-mail: dalmau@ cse.ufsc.br [Brasil]

\section{Carlos Augusto Harger}

Mestrando no Programa de Pós-Graduação em Administração pela Universidade Federal de Santa

Catarina - UFSC

E-mail: cau.harger@gmail.com [Brasil]

\section{Resumo}

O artigo apresenta um panorama de como está estruturado o processo de cooperação entre a Universidade e o segmento empresarial em níveis mundiais e propõe diretrizes para implementação e fortalecimento do processo nas universidades latino-americanas. Os resultados do estudo indicam que a transferência de conhecimentos é uma prática rotineira em universidades asiáticas, europeias e norte-americanas, especialmente a partir do século XIX com o advento da Universidade da Pesquisa. O surgimento de uma nova Universidade, muito mais aberta, interativa e empreendedora, em todas as suas frentes de atuação, fica evidenciado no pensamento dos autores que compõem o texto, e consolida a máxima acadêmica de que a Universidade somente poderá cumprir seus princípios e finalidades se tiver liberdade para produzir, sistematizar e disponibilizar para a sociedade os seus resultados de pesquisas e projetos educacionais. Propõe-se a criação de uma Agência de Inovação Tecnológica, como agente importante na interface desse novo modelo de Universidade, alinhada com as necessidades da sociedade e tendências de um mundo globalizado

Palavras-chave: Universidade, transferência de conhecimento, agência de Inovação.

RAI - Revista de Administração e Inovação ISSN: 1809-2039

Organização: Comitê Científico Interinstitucional

Editor Científico: Milton de Abreu Campanario

Avaliação: Double Blind Review pelo SEER/OJS

Revisão: gramatical, normativa e de formatação

RAI - Revista de Administração e Inovação, São Paulo, v. 6, n. 3, p. 128-144, set./dez. 2009. 


\section{INTRODUÇÃO}

A Universidade destaca-se no cenário mundial como uma das instituições mais importantes da sociedade, principalmente quando se consideram as exigências das economias globalizadas e o processo de inovação e mudanças contínuas nas organizações e na sociedade. Efetivamente, essa instituição secular vem desempenhando um papel determinante na sociedade na qual se insere, seja exercendo sua função precípua de ensino na formação de cidadãos e profissionais para o mercado de trabalho, seja nas funções pesquisa e extensão, contribuindo com o desenvolvimento e/ou aperfeiçoamento de grandes invenções colocadas a serviço da sociedade.

As universidades, já dissertava Drucker (1999), caracterizam-se como instituições de serviço e possuem responsabilidades sociais muito importantes. Elas não diferem muito das demais organizações, especialmente no que se refere aos encargos de seus administradores, ao seu planejamento e à sua estrutura organizacional. Entretanto, possuem valores e objetivos em que a diferença está, fundamentalmente, nas finalidades. Seu cliente não é realmente um cliente da forma como o conhecemos, ele é um contribuinte. Contribui financeiramente, independentemente de usá-la ou não, com seus impostos, contribuições ou alocação de custos indiretos. Sobretudo, seu produto não serve para satisfazer desejos e necessidades individuais, mas sociais. Finalmente, o autor classifica-as como organizações típicas de sociedades desenvolvidas.

A Universidade, especialmente nas últimas décadas do século $\mathrm{XX}$, conforme acentua Didrikson (2000), deslocou seus interesses por cultura e conhecimento geral, universal ou meramente profissional e técnico. Vive, portanto, um de seus momentos paradoxais. Ao mesmo tempo em que se vê amarrada às suas bases históricas, está diante de uma realidade global impositiva, que a remete a um comprometimento social mais eficaz.

Pode-se conjecturar, a partir do cenário paradigmático deste século XXI, que a Universidade está vivendo um dos seus momentos mais significativos desde suas origens, contudo, notadamente a partir da segunda metade do século $\mathrm{XX}$, quando o conhecimento universal, sobretudo nas áreas científica e tecnológica, tem gerado mais conhecimento do que os períodos que marcaram o restante da história da humanidade. Todavia, a adaptação da instituição universitária às mudanças exigidas pelo mercado enseja, certamente, uma reflexão bastante criteriosa, haja vista os princípios e finalidades que a têm norteado ao longo dos séculos.

\section{O CONHECIMENTO E O MUNDO ORGANIZACIONAL}

A transição de uma sociedade industrial para uma baseada no conhecimento e na informação tem trazido grandes mudanças para o ambiente social e organizacional. Vive-se neste século XXI um dos raros momentos da história, um momento mesclado de oportunidades e de grandiosos desafios, com regras e estilos que refletem direta e indiretamente na maneira de viver das pessoas e dos sistemas organizacionais.

O conhecimento é a nova moeda de troca. As organizações sociais estão inseridas neste ambiente dinâmico, de crescente competitividade e mudanças radicais e contínuas, supostamente ainda não enfrentados desde a Revolução Industrial. São tempos em que diuturnamente, se quebram e/ou surgem novos paradigmas, que exigem modernas abordagens pessoais e profissionais.

A globalização dos mercados está submetida ao conhecimento, à competência individual, ao aparecimento de competidores cada vez mais empreendedores, e nesse contexto

RAI - Revista de Administração e Inovação, São Paulo, v. 6, n. 3, p. 128-144, set./dez. 2009. 
turbulento, o conhecimento que gera inovação é regra geral. Mas ele deixa de ser apenas uma ferramenta e transforma-se no caminho pelo qual as ideias, sistemas e pessoas se convertem em valor agregado. A inovação exige pessoas com habilidades criativas que estejam receptivas ao novo continuamente.

As organizações têm em suas mãos um enorme desafio suportado pelos avanços científicos e tecnológicos. Elas estão sendo motivadas pela necessidade de responder a um mercado globalizado que se expande. Diante dessa realidade, infelizmente, em uma parte significativa de organizações, o horizonte parecerá cada vez mais nebuloso, especialmente para as que insistirem em continuar copiando o que fazem os concorrentes.

A alternativa de sobrevivência está na capacidade que as empresas terão de dar um giro radical em seus planos estratégicos, fazer predominar a inovação em oposição à imitação, ou seja, definitivamente colocar o conhecimento a serviço da geração de valor e fazê-lo mais rápido que a concorrência e de forma constante.

Nesse turbilhão, a crise institucional e o crescente índice de desemprego atingiram países com solidez empresarial como a Inglaterra, o Japão, os Estados Unidos, o Canadá e a Alemanha. Todos esses fatos, a rigor, têm contribuído substantivamente para o desequilíbrio de economias e do sistema de produção do mundo inteiro, principalmente nos países emergentes, como é o caso do Brasil, Rússia, Índia e China, refletindo na sociedade como um todo.

Se o século XX pode ser considerado como um grande e fecundo laboratório, uma incubadora de modelos organizacionais, denominado por pensadores da Administração como o século das organizações, o século XXI inicia-se com a crise dos modelos administrativos sedimentados. O modelo de produção preconizado por Taylor e aplicado por Ford, no início do século passado, está sendo delineado por novos processos e estratagemas provenientes de uma nova maneira de olhar o mundo, as pessoas e o meio ambiente. Em todos os países desenvolvidos, argumenta Drucker (1999), a sociedade transformou-se em uma sociedade de organizações.

Diante de um cenário econômico de crescente competitividade, em que é cada vez maior o desafio de reunir as condições fundamentais para o crescimento sustentável, o futuro de organizações sociais como as universidades passa, necessariamente, por repensar sua estrutura, modelo de gestão e posicionamento perante as ondas de mudanças que vêm ocorrendo na sociedade. Se por um lado há avanços consideráveis em sua estrutura e funcionamento, por outro, há tradicionalismos e corporativismos, incompatíveis com a contemporaneidade e a velocidade das mudanças e inovações exigidas pelo mercado e pela sociedade.

Em função dessa realidade, essa investigação tem como objetivo principal conhecer e analisar o processo de transferência de conhecimentos científicos e tecnológicos das Universidades latino-americanas e caribenhas para o segmento empresarial. Para dar suporte ao objetivo geral, foram escolhidos os seguintes objetivos específicos: 1) averiguar o estado da arte do processo de transferência de conhecimentos científicos e tecnológicos das Universidades para o segmento empresarial; 2) conhecer e propor diretrizes para a interface entre as universidades e o segmento empresarial.

\section{A TRANSFERÊNCIA DE CONHECIMENTOS CIENTÍFICOS E TECNOLÓGICOS DAS UNIVERSIDADES PARA O SEGMENTO EMPRESARIAL}


A transferência de conhecimentos científicos e tecnológicos resultante da parceria entre a Universidade e o segmento empresarial é realidade e prática rotineira em economias como Japão, Estado Unidos, Canadá, Inglaterra e Alemanha. Nesses países, já se consolidou a ideia de que a parceria entre esses segmentos é um dos mecanismos fundamentais para incrementar a competitividade, o desenvolvimento científico e tecnológico e a difusão de tecnologias. Além disso, a interface apresenta-se como uma estratégia importante na consolidação de uma economia empreendedora, moderna, que deverá contribuir significativamente para a melhoria dos indicadores socioeconômicos das nações.

Em países emergentes, como é o caso da China, da Rússia, da Índia, da Coréia do Sul, do México e do Brasil, a parceria que gera transferência de conhecimentos científicos e tecnológicos do segmento acadêmico para o empresarial destaca-se como um dos principais instrumentos de difusão de tecnologias indutoras de desenvolvimento.

Os avanços científicos e tecnológicos em níveis globais, especialmente em áreas estratégicas, como telecomunicações, infotecnologia, robótica, biotecnologia, nanociência e nanotecnologia, alcançaram níveis espantosos. Apenas para exemplificar, a nanotecnologia saiu da ficção, deixou de ser um modismo nos países com maior potencial de investigação, e acionou o sinal de alerta nos ambientes científicos e tecnológicos do mundo inteiro. Cientistas do campo da Física, Química, Biologia, Matemática e Engenharias estão voltando seus esforços para acelerar as descobertas na busca pela expertise que possibilite a construção de nanomáquinas que os permitirá entrar e manipular esse estranho, complexo e desafiante Universo, o nanomundo. O controle das nanopartículas já é uma realidade e está permitindo ao homem criar tecnologias inteiramente novas com impacto na economia e demais áreas do conhecimento.

Avanços importantes são apresentados à sociedade também nas áreas médica, biomédica, energética e agropecuária. Eles geralmente começam nos laboratórios das universidades, nos centros de excelência ou nas grandes empresas, em parceria com pesquisadores provenientes dessas instituições.

Com a reconfiguração sócio-político-econômica, a ciência do século XXI mudou de ritmo, deixou de caminhar e começou a dar saltos cada vez maiores e com maior velocidade. Em razão dessa dinâmica, vem surpreendendo e preocupando o segmento industrial de todos os níveis, não apenas de países desenvolvidos, mas principalmente dos países em desenvolvimento que, despreparados e desprovidos de práticas inovadoras, de laboratórios e de potencial humano para pesquisa, se veem obrigados a voltar seus olhos para um dos poucos lugares privilegiados na geração de novos conhecimentos: a Universidade.

Autores acadêmicos e representantes de empresas promovem a cooperação como uma oportunidade inédita de transferência de novas tecnologias desenvolvidas nas Universidades para o setor produtivo, que, por consequência, reverterá em benefícios para toda a sociedade. Por outro lado há os que, quando não a refutam integralmente, buscam discutir a transparência do processo, identificando vantagens, ações ou perigos na parceria. Se não podem impedi-la pelas circunstâncias e tendências do mercado e da própria dinâmica acadêmica, procuram cercar-se de meios seguros da manutenção do atual status quo. Partem do pressuposto que é preciso defender a Universidade como um patrimônio inalienável da sociedade.

Percebe-se, na Universidade, que a discussão a respeito de suas relações com o setor produtivo tem-se caracterizado como um tema recorrente e paradigmático. O que se observa, todavia, é que independentemente de seus protagonistas, a cooperação está crescendo muito rapidamente. Se as instituições e as pessoas não estão preparadas, são pegas de surpresa e 
ARTIGOS - Transferência de Conhecimentos Científicos e Tecnológicos da Universidade para o Segmento Empresarial

podem sofrer revezes irreparáveis em seu patrimônio e em suas vidas, ou até mesmo perdêlas.

Em alguns países latino-americanos, como Brasil, Chile e Argentina, a onda da cooperação, de certa maneira, já não é tão ameaçadora, tendo em vista que já se faz presente e incorporada às rotinas de muitas instituições. Essa realidade, por conseguinte, tem propiciado aos interessados na questão, favoráveis ou não, inesgotáveis fontes de reflexão e discussão.

A inovação constante nos produtos e serviços, exigida pela nova ordem mundial, de certa forma, está impondo às universidades, sejam elas públicas ou privadas, o desafio da produtividade e competitividade, questionando-as e colocando-as frente a frente com seus valores e paradigmas mais sedimentados.

\section{DIMENSÕES DO PROCESSO DE TRANSFERÊNCIA DE CONHECIMENTOS DA UNIVERSIDADE PARA O SEGMENTO EMPRESARIAL}

A exemplo do que ocorreu na Europa, na América do Norte e em alguns países da Ásia, como China, Japão, Coreia do Sul, Hong Kong e Taiwan, a parceria entre as universidades latino-americanas e o segmento empresarial deverá inserir- se nesse novo contexto mundial, mesmo despontando como uma temática das mais polêmicas discutidas hoje no âmbito desses segmentos.

O papel da cooperação Universidade Segmento Empresarial e sua relevância para o desenvolvimento econômico e social de universidades da América Latina, de acordo com Plonski (1999), tem como marco o ano de 1968. Naquela ocasião, o diretor da Comissão Nacional de Energia Atômica para a Argentina, Jorge Sábato, e Natálio Botana, pesquisador do Instituto para Integração da América Latina, entenderam e propuseram que, para a superação do desenvolvimento da região e seu acesso à condição de sociedade moderna, fosse realizada uma ação decisiva no campo da pesquisa científico-tecnológica. Para esses estudiosos, a América Latina estava apenas começando a se conscientizar da importância dessa questão. Os estudos de Sábato e Botana culminaram com o que viria a ser chamado de Triângulo de Sábato. Entendiam que para a participação da região no desenvolvimento científico e tecnológico seria fundamental que houvesse uma ação conjunta do governo, da estrutura produtiva e da infraestrutura científico-tecnológica.

Essa configuração foi apresentada graficamente como um triângulo apoiado numa base, em que o governo ocupa o vértice superior e os demais elementos, os vértices da base. Para Plonski (1999), no Triângulo de Sábato ocorrem três tipos de nexos: intrarrelações entre os componentes de cada vértice; inter-relações, que se estabelecem entre os pares de vértices e extrarrelações, que são as que se criam entre uma sociedade e o exterior.

Alguns dos princípios estabelecidos pelo Triângulo de Sábato ainda permanecem na agenda da América Latina: a necessidade vital de dinamizar as relações entre os atores e o reconhecimento da dificuldade de estabelecer as inter-relações horizontais. Entende o autor que isso representa uma pista do porquê de a cooperação universidade-empresa começar a tomar fôlego na região apenas na década de 1990. Assim, três instrumentos criados em 1990 se constituem no divisor de águas nos esforços da cooperação nos países respectivos: a Lei de Promoção e Fomento à Pesquisa Tecnológica, na Argentina; a Lei Marco da Ciência e Tecnologia, na Colômbia e a Política Industrial e de Comércio Exterior, no Brasil, com os programas de apoio à capacitação tecnológica da indústria e de qualidade e produtividade dela decorrentes (PLONSKI, 1999).

RAI - Revista de Administração e Inovação, São Paulo, v. 6, n. 3, p. 128-144, set./dez. 2009. 


\section{DIRETRIZES PARA A COOPERAÇÃO UNIVERSIDADE E SEGMENTO EMPRESARIAL NA AMÉRICA LATINA E CARIBE}

Propor diretrizes para um modelo de cooperação pode ensejar uma enormidade de reflexões e questionamentos que, a rigor, poderiam inviabilizar as recomendações aqui apresentadas. Entretanto, a proposta que se coloca em discussão não representa um modelo definitivo, que exija a implementação imediata de todos os seus aspectos, ou parte deles, mas serve como parâmetro, se considerarmos que está suportada pela experiência vivenciada por universidades representativas da região e que estão à frente do processo.

Experiências exitosas nas áreas de transferência de conhecimento em todo o mundo têm demonstrado que um processo de cooperação eficaz passa, necessariamente, pela existência de determinados agentes que dão suporte à interface. Sem eles, o processo torna-se fragmentado, não institucional e corre o risco de trazer mais malefícios do que benefícios para a instituição. Na sequência, apresentam-se os requisitos e ações entendidos como fundamentais para a ocorrência de um processo de cooperação, no âmbito da Universidade, Governo e Segmento Empresarial.

\subsection{UNIVERSIDADE}

Autonomia: a autonomia é a base da cooperação entre as Universidades e o segmento empresarial. Pode-se afirmar que é imprescindível e sem ela as universidades, especialmente as públicas, não podem sequer pensar em estabelecer parcerias, porque normalmente se encontram enredadas pelo excesso de leis e burocracias, próprias do aparato estatal.

Comunicação: a comunicação é um pré-requisito fundamental a ser considerado na parceria. Um sistema integrado de rádio, TV, jornal e Internet sempre podem valorizar as ações da Universidade, principalmente quando notificam seu potencial humano, resultados de pesquisas ou os projetos em andamento. A falta desse mecanismo de interface tem se caracterizado como um dos maiores empecilhos para a cooperação. $\mathrm{O}$ conhecimento restrito a grupos de saberes específicos ou armazenamento de ideias tem sido uma prática rotineira na história da Universidade. É a sabedoria dos papéis, da prateleira, dos congressos entre pares e dos vastos currículos para ostentação. No Brasil, está em processo de sedimentação a RedeIFES que atualmente está estruturada em 20 rádios universitárias distribuídas em 19 Instituições Federais de Ensino Superior. Conta, ainda, com 24 TVs universitárias e outras cinco em processo de implementação ou concessão. Por esse sistema, as instituições estão interligadas, o que permite a disponibilização em tempo real de conteúdos multimídia. Essa rede objetiva, em parceria com TV pública potencializa a produção e a divulgação de conteúdo acadêmico, produzido nas universidades.

Formação do Capital Intelectual: a interface entre os três segmentos tem como suporte um bem intangível e verdadeiramente imprescindível que é o capital intelectual que dá suporte às instituições. Nesse caso, somente instituições que investem na formação de cérebros podem interagir com sucesso. $\mathrm{O}$ desenvolvimento contínuo de profissionais técnicoadministrativos, professores e pesquisadores é um dos principais fatores de desempenho das instituições nessa área. Um quadro de pessoas altamente qualificadas, especialmente nos níveis de mestrado e doutorado no exercício das funções ensino, pesquisa e extensão, torna possível a criação de novos saberes. Nesse sentido, as instituições devem propiciar os meios para que a equipe de profissionais esteja permanentemente em processo de desenvolvimento e potencialização.

RAI - Revista de Administração e Inovação, São Paulo, v. 6, n. 3, p. 128-144, set./dez. 2009. 
ARTIGOS - Transferência de Conhecimentos Científicos e Tecnológicos da Universidade para o Segmento Empresarial

Formação e Capacitação de Dirigentes: a Universidade precisa criar mecanismos de formação e capacitação dos dirigentes na área de gestão universitária. As lideranças devem estar preparadas não apenas para atender e solucionar as necessidades acadêmicas, mas também para gerenciar um moderno e complexo sistema de interação com a sociedade e seus diversos setores, entre eles o empresarial. Precisa formar dirigentes que estejam conscientes da realidade global, que tenham visão holística, que estejam prontos para exercer os quatro pilares fundamentais da aprendizagem, preconizados por D'Elors (1998), ou seja, aprender a conhecer, aprender a fazer, aprender a viver juntos e aprender a ser. É importante que saibam, ainda, interagir com tecnologia da informação e comunicação, com redes internacionais, que conheçam os modernos processos administrativos, sistemas integrados de gestão e que saibam administrar os entraves burocráticos próprios da administração pública. Sobretudo, devem ser preparados para ser e fazer acontecer o pensar criativo da equipe, que exerçam a liderança participativa, que sejam capazes de reconhecer competências e o potencial individual dos colaboradores, ou seja, que conheçam e saibam trabalhar com pessoas.

Fundos de Incentivo à Pesquisa Institucional: a criação de fundos de incentivo à pesquisa institucional pode gerar um sinergismo que alcançará proporções inimagináveis no processo de formação acadêmica, seja na graduação, seja na pós-graduação, especialmente em projetos de iniciação científica, em que o aluno terá seu primeiro contato com a pesquisa. Além disso, esses fundos têm a função de possibilitar aos alunos e professores a participação em congressos ou eventos científicos. Os recursos desses fundos podem ser provenientes de percentuais subtraídos de projetos de cooperação, fundações de apoio à pesquisa, cursos de especialização e aperfeiçoamento e até mesmo do próprio orçamento da universidade. Os fundos de pesquisa devem ser amplos, atingindo a todas as áreas de atuação da Universidade, de tal sorte que qualquer pesquisador docente ou discente possa beneficiar-se deles.

Pesquisa Científica e Tecnológica: a pesquisa científica e tecnológica na Universidade está pautada pela busca sistemática e planejada de novos conhecimentos e métodos de produção de bens de consumo e de serviços. Este é um requisito fundamental para o processo de cooperação. Sem pesquisa, a interface é praticamente impossível, porque a empresa espera resultados inovadores, enquanto a Universidade precisa gerar continuamente novos conhecimentos.

Laboratórios de pesquisa: laboratórios com infraestrutura e tecnologia de ponta estão na base da criatividade e da inovação e podem refletir no nível da pesquisa desenvolvida. A empresa busca resultados concretos e inovadores; para atingi-los, vai apostar em universidades que possuam laboratórios com pessoas competentes que desenvolvam pesquisas que resultem em um produto comercializável. Quando a empresa escolhe os laboratórios de uma universidade para fazer um estudo de um projeto que culminará num produto final é porque sabe que ali tem gente para fazer isso com qualidade e confiança nos resultados.

Legislação e Centralização do Processo de Cooperação: a legislação no processo de transferência de conhecimentos é fundamental. Sem ela o processo fragmenta-se e foge ao controle da instituição. É preciso definir os procedimentos com regras claras. A formalização de contratos deve ser um processo básico. Nesse caso, é preciso centralizar o processo no gabinete do reitor, do vice-reitor ou pró-reitoria de pesquisa e extensão, ou melhor ainda, criar uma Agência de Inovação Tecnológica. A centralização e amparo em bases legais solidificam o processo de cooperação.

A fragmentação, o descontrole e desconhecimento institucional nas parcerias põem em risco os princípios e finalidades da Universidade. Uma relação desregulamentada permite aos

RAI - Revista de Administração e Inovação, São Paulo, v. 6, n. 3, p. 128-144, set./dez. 2009. 
envolvidos receberem recursos desordenadamente e até mesmo de maneira ilegal. Não se pode desconsiderar que, sem um controle institucional e eficaz na execução desse tipo de trabalho, com pelo menos estabelecimento de carga horária e uso da máquina institucional, pode ocorrer desvios de interesse por parte dos pesquisadores, além de o trabalho acadêmico correr o risco de se tornar enfadonho e desinteressante.

A transferência de conhecimentos da Universidade não pode ocorrer de maneira fragmentada, fragilizada e sem regras disciplinatórias. Na prática, sabe-se que o processo ocorre isoladamente, e muitas vezes sem a anuência da própria instituição. Normalmente, o processo fundamenta-se nas relações diretas entre pesquisador e empresa, mas a responsabilização civil pelo processo é da Universidade.

\subsection{SEGMENTO EMPRESARIAL}

$\mathrm{Na}$ America Latina está sedimentada a ideia, tanto no meio acadêmico como no empresarial, que pesquisa é coisa de Universidade. E, por conta dessa ideologia, também se cultivou o modelo de Universidade que desenvolve tecnologia. Em função dessa cultura, quase a totalidade das atividades das universidades é voltada para a pesquisa científica e inovação tecnológica. Contudo, o sucesso da cooperação não pode ficar apenas a mercê do potencial científico e tecnológico do segmento universitário. Países altamente desenvolvidos reconhecem que o segmento empresarial tem que dar sua contribuição à ciência. Nos Estados Unidos, país mais industrializado do mundo, mais de $80 \%$ dos doutores que saem das universidades estão no ambiente empresarial, enquanto na América Latina e Caribe esta realidade é inversamente proporcional.

A contratação de doutores pelas empresas é uma iniciativa que leva à conjugação de conhecimentos, à efetividade e à competência científica entre os dois segmentos. A iniciativa pode ocorrer pelo menos de duas formas, por contratação ou por meio de bolsas concedidas ao doutores, em parcerias com universidade ou centros de pesquisas.

\subsection{GOVERNO}

$\mathrm{Na}$ composição tríplice do processo de cooperação que gera transferência de conhecimentos, o governo tem um papel relevante no estímulo, proposição de leis e implementação de ações que resultem em mais ciência e tecnologia. A participação do Estado torna-se fundamental, porque ele ainda é o principal financiador das universidades latinoamericanas e caribenhas. Pressupõe-se, assim, que o Estado deverá comprometer-se, efetivamente, com:

Investimentos em Educação, Ciência e Tecnologia: o investimento em educação, ciência e tecnologia é imprescindível para que o governo possa estar efetivamente incluído nesta tríplice aliança. Sem ele os demais segmentos acabam sendo prejudicados, especialmente quando se considera que alguns elementos desse processo são requisitos sine qua non para a existência e a afirmação da ciência como agente propulsor da criatividade e da inovação.

Se o Governo não faz investimentos em um sistema de pós-graduação forte, que tenha como meta a formação de pessoal em nível de mestrado e doutorado, a pesquisa não se faz presente. Sem uma infraestrutura de trabalho e de salários, com pesquisadores capacitados e laboratórios compatíveis com os níveis requeridos pela ciência moderna, também não deverá haver pesquisa. 
Os países latino-americanos ainda investem pouco em educação, ciência e tecnologia. Quando se considera o montante aplicado por países altamente desenvolvidos como Estados Unidos, Alemanha, Japão, Canadá, esse percentual está muito aquém do necessário, o que acaba por refletir em um baixo nível tecnológico e de competitividade, muito distantes do patamar necessário. Tome-se como exemplo o Brasil, a décima economia do mundo e primeira da América Latina, e a Argentina, a segunda economia da América Latina, mas que investem do PIB não mais do que $0,80 \%$ e $0,56 \%$ em educação e $0,65 \%$ e $0,49 \%$, em ciência e tecnologia, respectivamente (INSTITUTO INTERNACIONAL PARA LA EDUCACIÓN SUPERIOR EM AMÉRICA LATINA Y EL CARIBE, 2008).

Secretaria de Desenvolvimento Científico e Tecnológico: a criação de uma secretaria de desenvolvimento científico e tecnológico, em nível estadual, é um dos caminhos possíveis para a centralização e difusão de políticas públicas de investimentos na área. A criação desse organismo permite a organização em níveis macros do processo e tem como objetivo financiar e estimular pesquisadores, universidades e centro de pesquisas, na busca pelo conhecimento novo. Ela serviria, ainda, como agente centralizador de interface entre agentes articuladores da cooperação, como as agências de inovação tecnológica, escritórios de transferência de tecnologia, redes e incubadoras de base empresarial e tecnológica, e os demais agentes.

\subsection{AÇÕES CONJUNTAS: UNIVERSIDADE, SEGMENTO EMPRESARIAL E GOVERNO}

Polos e Parques Tecnológicos: o ápice da tríplice aliança, Universidade, Segmento Empresarial e Governo está na criação de polos e parques tecnológicos. Eles podem ser considerados um segundo estágio mais avançado do processo e indicam a maturidade da relação e o momento de colher os resultados mais expressivos. Nos polos e parques tecnológicos há uma expectativa muito grande de que eles sejam ambientes transformadores das pesquisas levadas a cabo nas universidades e centros de pesquisa. É sabido que a inovação não ocorre, necessariamente, dentro das Universidades, mas quando esta transfere o conhecimento para o Segmento Empresarial.

Os polos e parques tecnológicos são projetos importantes, na medida em que estão voltados de maneira constante para os setores que precisam do desenvolvimento de novas tecnologias, como é o caso das empresas.

Apoio às Micro e Pequenas Empresas: o segmento empresarial latino-americano está fundamentalmente organizado com micro e pequenas empresas. Esse, portanto, é um segmento em que os três atores, Universidade, Governo e Segmento Empresarial, devem unir forças. Se considerarmos que a grande base da pirâmide organizacional no mundo inteiro é formada por empresa desse porte, há que se tomar consciência dessa realidade e tentar fortalecê-la.

Propriedade Intelectual e Patentes: a América Latina e o Caribe são detentores de uma riqueza biológica extraordinária. Embora essa realidade seja conhecida de todo o mundo, pouco se conhece de sua biodiversidade, especialmente da Amazônia - seja por sua imensidão e escassez de pesquisas e estudos, seja pela falta de divulgação no âmbito regional. Fato preocupante também é o desconhecimento do potencial que essa diversidade biológica pode representar para o desenvolvimento econômico e social dos países que compõem a região.

O patenteamento de produtos e serviços já é regra geral no segmento empresarial. Entretanto, o segmento universitário ainda não tem know-how nem estrutura financeira nessa

RAI - Revista de Administração e Inovação, São Paulo, v. 6, n. 3, p. 128-144, set./dez. 2009. 
área. Felizmente, há indicativos de que começa a se interessar pela questão. Muitas instituições estão criando mecanismos reguladores ou discutindo a importância de aprovar legislação específica, mas isso é uma cultura que deverá ser implantada muito lentamente, especialmente considerando que o investimento é alto.

Incubadoras de Base Tecnológica e Empresarial: a criação de incubadoras de base tecnológica e empresarial vem crescendo em larga escala no mundo inteiro. Esse fato ocorre, predominantemente, pela necessidade das universidades sintonizarem suas relações com o segmento empresarial e também pela visão empreendedora que começa a se firmar em determinados segmentos da vida acadêmica. A implementação de incubadoras permitiria o surgimento de condições e facilidades necessárias para o desenvolvimento de novas empresas e negócios, gerando emprego, renda e desenvolvendo a cultura empreendedora nas comunidades. As incubadoras estão assentadas sobre o eixo de provisão de serviços ou ativos do conhecimento. Dentre as ações e fatores de êxito destacam-se: a) criação de empresas e geração de empregos com altos valores agregados de conhecimento; b) prestação de serviços de apoio como provisão de espaço físico; c) acesso a serviços gerais, administrativos ou serviços de consultoria; d) interação e apoio das universidades; e) disponibilidade de fundos de capital inicial, fundos de capital de risco; f) incorporação de talento humano de alta qualificação; g) inovação radical de produtos e processos (COLCIENCIAS, 2008).

\section{AGÊNCIA DE INOVAÇÃO COMO MECANISMO DE INTERFACE PARA A TRANSFERÊNCIA DE CONHECIMENTOS CIENTÍFICOS E TECNOLÓGICOS}

A Universidade é uma instituição consagrada no contexto político, econômico e social dos países, sobretudo, por suas ações extensionistas e de cooperação com a sociedade. Ao longo de seus mais de oito séculos de existência, e fundamentalmente a partir da criação da Universidade da Pesquisa, na Alemanha, e Universidade da Extensão, nos Estado Unidos, no século XIX, consolidadas no século XX, vem assumindo posições de destaque que lhe asseguram um caráter inovador, uma identidade de competências e de responsabilidades poucas vezes experimentados por outra instituição. Enquanto agente indutor de conhecimentos e construtor de uma nova realidade social, a Universidade se estabelece como uma das instituições de maior relevância na construção de um mundo melhor.

As iniciativas acontecem em todas as áreas de atuação, seja formando profissionais para atender a demanda da sociedade, seja pesquisando e colocando à disposição dessa sociedade os resultados de seus conhecimentos.

O que se observa, contudo, é que muitas de suas ações ainda estão num estágio muito incipiente. Se a formação de bons profissionais tem merecido o reconhecimento da sociedade, o mesmo não ocorre nas demais áreas com tamanha intensidade. Embora os avanços na pesquisa sejam muitos, e representativos, muito ainda há que se fazer, principalmente tornar disponíveis os resultados. Sendo assim, acredita-se que, para a sociedade usufruir dos benefícios da pesquisa, é necessário que a instituição universitária latino-americana faça um redimensionamento dessa área, revendo suas políticas de transferência de conhecimentos científicos e tecnológicos, o que, por si só, já requer uma reflexão profunda.

Nesse sentido, propõe-se a criação de uma Agência de Inovação e Transferência de Conhecimentos Científicos e Tecnológicos, a qual serviria como mecanismo capaz de minimizar as dificuldades apresentadas e ampliar uma história de sucesso e credibilidade junto à sociedade. Além de aprofundar suas relações com a sociedade, num exemplo vivo de retorno ao que dela recebe, a Universidade poderá, a partir desse ato, contribuir significativamente para o desenvolvimento do parque industrial dos países, colocando à

RAI - Revista de Administração e Inovação, São Paulo, v. 6, n. 3, p. 128-144, set./dez. 2009. 
disposição do segmento empresarial de micro, pequenas, médias e grandes empresas todo o conhecimento científico e tecnológico resultante de suas pesquisas.

Uma Agência dessa natureza pode representar uma oportunidade de a Universidade se estabelecer definitivamente como uma instituição que tem vocação para a pesquisa e fortalecer a Extensão como uma de suas práticas mais fortes; sobretudo, voltar-se ao atendimento de demandas sociais concretas e buscar uma aproximação definitiva com a sociedade.

A Agência deverá estabelecer um novo paradigma para a reorganização da pesquisa científica na Universidade. Adicionalmente, irá incentivar e oportunizar por meio de um programa multidisciplinar a pesquisa básica ou aplicada de caráter inovador, de modo a permitir que o conhecimento gerado seja transferido para os diversos segmentos da sociedade, subsidiando um novo olhar, uma nova maneira de trabalhar as políticas estabelecidas para as universidades, ou ainda, como propõe Yunus (2000), a Universidade deverá deixar transbordar um pouco desse saber para as populações vizinhas e assim mostrar sua totalidade.

A Agência deverá ter, no âmbito externo, a tarefa de estabelecer interfaces com as demais Instituições de Ensino Superior, com os organismos de fomento à pesquisa, além de viabilizar parcerias com organizações governamentais, com Federações das Indústrias, com representantes das associações de micro e pequenas empresas, e com o terceiro setor, ou seja, cooperativas, fundações e organizações não governamentais (ONGs), entre outros organismos que estimulam o desenvolvimento das Micro Pequenas e Médias Empresas - MPME's, o maior universo empresarial da América Latina.

Além disso, deve constituir-se como uma entidade referencial e de interfaces entre os centros de ensino, departamentos e pesquisadores, assumindo a responsabilidade pela centralização de todos os projetos científicos e tecnológicos já desenvolvidos ou em desenvolvimento nas universidades, permitindo a interdisciplinaridade e uma dinâmica jamais vista antes na Instituição.

\subsection{MISSÃO E OBJETIVOS DA AGÊNCIA}

A Agência deverá ter como missão precípua: fortalecer as relações de cooperação da Universidade com a sociedade organizada, em especial, com o segmento empresarial e deverá ter como objetivos:

a) No âmbito Interno: construir um sistema de parcerias que permita a interdisciplinaridade entre as funções de ensino, pesquisa e extensão com os segmentos representativos da comunidade acadêmica, estabelecendo relações entre os diversos centros de ensino, faculdades, institutos e departamentos;

b) Na Comunidade Local: estimular o desenvolvimento de um ambiente capaz de atrair investimentos baseados no conhecimento e a criação de empresas de base tecnológica, além de dar suporte às atuais instituições de pesquisa;

d) No País: contribuir com as políticas públicas de criação de um desenvolvimento sustentável, fortalecendo e incrementando o sistema de pesquisa e uma política de inovação tecnológica eficaz; apoiar, elaborar e implementar projetos que venham a contribuir com as políticas do Executivo;

d) Na América Latina e no Caribe: apoiar e fortalecer parcerias que permitam a integração entre as Instituições de Ensino Superior e demais centros de pesquisa 
visando, sobretudo, fortalecer o desenvolvimento da região latino-americana e caribenha.

e) No Mundo: Estabelecer interfaces com centros de pesquisas, universidades, agências similares, ONGs e organismos internacionais, como a UNESCO.

A Agência deverá desenvolver pelo menos cinco grandes linhas de ação:

1) Ser um agente assessor de Dirigentes e Pesquisadores da Universidade, na formação de parcerias com o segmento empresarial, instituições de ensino e pesquisa, agências de fomento, visando à geração e à difusão de conhecimento e tecnologia;

2) Organizar e divulgar a capacitação tecnológica da Universidade;

3) Estimular o desenvolvimento de uma cultura empreendedora, envolvendo discentes, docentes e pessoal técnico-administrativo;

4) Apoiar a prospecção das fontes de financiamento nacionais e internacionais à pesquisa e aos programas de transferência de tecnologia;

5) Estimular, capacitar e assessorar dirigentes, pesquisadores e técnicoadministrativos da Universidade na proteção da propriedade intelectual e na transferência de tecnologia.

\subsection{Base de Especialistas e de Pesquisas}

A criação de um banco de dados de especialistas no âmbito da Agência permitirá aos públicos interno e externo visualizar o referencial científico e tecnológico existente na instituição. Essa base de dados deverá se constituir de pesquisadores da Universidade, especialistas por área de competência, que estejam ou que tenham desenvolvido algum tipo de experiência nas áreas de ensino, pesquisa e extensão. Deverá ter como objetivos: disseminar o potencial humano existente na instituição e difundir conhecimentos científicos e tecnológicos tanto no âmbito interno como no externo. A Internet será a ferramenta básica, que permitirá o acesso irrestrito e gratuito aos dados institucionais, de qualquer parte do país ou do mundo.

O banco de dados de pesquisas deverá servir como um agente indutor e difusor do conhecimento acumulado, além de servir como centro irradiador de novas pesquisas e de oportunidades à comunidade universitária. Esse banco permitirá à comunidade interna e externa conhecer os projetos desenvolvidos na instituição ao longo de sua existência. Evidentemente que esse tipo de banco de dados precisará buscar mecanismos de segurança que resguardem o direito de propriedade intelectual.

\section{3 ÓRGÃOS COMPLEMENTARES}

Visando dinamizar as ações a serem implementadas pela Agência, deverão ser criados ou incorporados à Agencia, órgãos que tenham como função dinamizar o processo de transferência de conhecimentos. Assim, pressupõe-se que sua estrutura inicial deverá conter pelos menos os órgãos abaixo discriminados.

a) Escritório de Transferência de Tecnologia - ETT

O ETT deverá ser um órgão complementar da Agência de Inovação e Transferência

de Conhecimentos Científicos e Tecnológicos cujo atributo principal será estabelecer 
uma rede de contatos entre os pesquisadores da instituição, os órgãos governamentais de fomento à pesquisa, as ONGs e o segmento empresarial.

Ele servirá de elo entre os diversos segmentos, institucionalizando relações, orientando parcerias e exercendo a interdisciplinaridade sempre que se manifestar a necessidade de integração entre as diversas áreas do conhecimento, no desenvolvimento dos projetos.

Dentre os principais objetivos de um escritório de transferência de tecnologia destacam-se: ser elo e estabelecer contatos com empresas; colaborar com os pesquisadores na orientação do projeto em face das necessidades das empresas; ajudar os pesquisadores na condução do processo de negociação de contratos de pesquisa tecnológica; relatar e negociar os contratos de transferência de tecnologia; acompanhar o desenvolvimento dos projetos contratados entre empresas e a Universidade; buscar financiamento para o projeto em fontes governamentais; assessorar as empresas sobre os diversos aspectos da administração da tecnologia; estabelecer proteção industrial e o registro de patentes, e, principalmente, divulgar os produtos da Universidade para a interação.

O escritório de transferência de tecnologia torna-se importante, especialmente quando se analisa a figura do pesquisador universitário. Essa figura tem suas atividades voltadas para o desenvolvimento de pesquisas, sejam elas básicas ou aplicadas dentro de sua área específica de atuação. O seu mundo é o estudo da ciência. Todavia, quando se depara com a necessidade de apresentar suas pesquisas e de estabelecer relações para transferência de tecnologia surgem problemas. Ele não está particularmente familiarizado com questões burocráticas que envolvem o processo. Além disso, torna-se difícil localizar nichos de mercado, negociar preços, vender seu produto, tendo em vista não ser esta sua área de atuação.

Cabe, também, ao escritório de transferência de tecnologia, servir como um minimizador de dificuldades ou barreiras ocasionais surgidas ao longo do processo da cooperação, seja como mediador, seja como esclarecedor para questões muitas vezes mistificadas com relação à universidade, por parte dos empresários e vice-versa (CUNHA, 2002).

b) Departamento de Gestão da Propriedade Intelectual

O Departamento de Gestão da Propriedade Intelectual deverá exercer, como principal função, o estímulo, a proteção jurídica e a exploração econômica das criações intelectuais. Desempenharia um papel auxiliar na negociação e redação de processos que induzam ao patenteamento de produtos e serviços, viabilizando a proteção do conhecimento científico e tecnológico produzido na Universidade.

c) Fundações de Apoio à Pesquisa

Considerando que as fundações de apoio têm uma função importante nesse processo, especialmente nos países em que as universidades não possuem autonomia, ou que possuam legislação centralizadora, sugere-se que para a criação da Agência de Inovação e Transferência de Conhecimentos Científicos e Tecnológicos haja a participação financeira dessas instituições, especialmente no que tange à implementação e à manutenção da Agência. 
As fundações deverão destinar $1 \%$ (um por cento) da receita bruta, resultante de projetos e outros tipos de ações administradas e/ou desenvolvidas por elas no âmbito da Universidade.

Esse dinheiro será a base de sustentação da Agência, em investimento em iniciação científica, difusão científica, publicações, congressos, conferências e outros meios de difusão da ciência.

\subsection{PROGRAMAS DE APOIO E COOPERAÇÃO}

A Agência deverá manter pelo menos dois programas importantes: Programa de Apoio a Micro e Pequenas Empresas e Programa de Cooperação Universidade-Universidade e Centros de Pesquisa:

a) Programa Apoio a Micro e Pequenas Empresas

O programa de apoio a Micro e Pequenas Empresas deverá se consolidar como um sistema de integração da Universidade com o segmento que representa a maioria absoluta dos empresários e é base da economia dos países latino-americanos e caribenhos. O programa promoverá iniciativas conjuntas que permitam identificar necessidades e capacitar o segmento, mediante aproveitamento do potencial tecnológico da Universidade. O programa proporcionará a esse segmento empresarial a oportunidade de buscar nos profissionais da Universidade uma parceria capaz de promover a inovação de seus produtos, processos ou serviços, minimizar suas deficiências, além de se qualificarem para aumentar a competitividade no mercado.

b) Programa permanente de Cooperação Universidade-Universidade e Centro de Pesquisas

O Programa de Cooperação Universidade-Universidade e Centros de Pesquisas deverá fortalecer o processo de integração, por meio da pesquisa, da Universidade com todo o sistema universitário e demais centros de pesquisa em nível regional. Além de permitir a criação de um sistema de parcerias, que possibilite a pesquisadores se unirem no desenvolvimento de projetos conjuntos, incentivará a exploração de temas que resultem em benefícios à pesquisa das instituições envolvidas.

\section{$7 \quad$ CONCLUSÕES}

O processo de transferência de conhecimentos científicos e tecnológicos da Universidade para o Segmento Empresarial já é um paradigma inevitável no contexto latinoamericano e caribenho. Diante do quadro de exclusão social, de miséria e analfabetismo, o fortalecimento da ideia de Universidade com responsabilidade social passa, necessariamente, pelo conceito de que educação é um bem público, um direito humano inalienável; neste princípio, entende-se que está implícita a ação direta da Universidade como instrumento de desenvolvimento do profissional, do ser humano cidadão e como detentora de um imenso potencial científico e tecnológico que deverá ser colocado a serviço da sociedade.

As mudanças no meio econômico e social são intensas, e as necessidades do mundo empresarial maiores ainda. Entretanto, mesmo diante de um mercado que cada dia mais pressiona por melhores desempenhos e de um cenário de globalização que remete a injustiças e fomenta a pobreza, a Universidade não pode limitar-se a uma visão economicista. O papel a ser desempenhado pela Universidade nesse contexto certamente deverá transpor uma de suas 
responsabilidades precípuas, ou seja, formar profissionais para o mercado de trabalho. Ela também deverá destacar-se como agente criativo e impulsionador de inovações científicas e tecnológicas que irão atender as demandas da sociedade, reafirmando seu papel de instituição comprometida com a responsabilidade social.

No que concerne ao pilar da tríplice aliança, Universidade, Segmento Empresarial e Governo, entende-se que o vigor das relações entre esses três segmentos deverá ensejar uma prática que leve ao desenvolvimento científico e tecnológico e ao equilíbrio econômico das nações. Nesse quesito, o Estado deverá exercer um papel fundamental, investindo maciçamente na educação, na área de ciência e tecnologia, na criação de leis que ordenarão o processo e na parceria com setores estratégicos, como a Universidade e o Segmento Empresarial. A perfeita articulação desses segmentos resulta em inovações que geram novos produtos e serviços, empregos, renda, impostos e maior competitividade. A experiência tem demonstrado que a cooperação quando chega a esse estágio resulta positivamente para os três segmentos, deixando aflorar as consequências em forma de benefícios para toda a sociedade.

Entende-se que o efetivo repasse e difusão de conhecimentos científicos e tecnológicos não deverá ocorrer apenas entre os três segmentos, mas também entre instituições de ensino, governos e empresas de toda a América Latina, fortalecendo as relações e a competitividade no mercado internacional. Deverão ser criados mecanismos que reforcem a interface entre os três segmentos, especialmente no que tange à legislação; disseminar, incentivar e implementar a criação de incubadoras de base empresarial e tecnológica e parques tecnológicos; criar políticas publicas estratégicas que incentivem a ciência e tecnologia; criar um Agente de Interface que agregue os três segmentos.

A cooperação deve pressupor ações de maior envergadura, pois a Universidade não tem tecnologia de prateleira, não deve ter e nem incentivar ações dessa natureza. Porém, esse fato ocorre em função de haver uma distorção dos objetivos das universidades, em determinados setores acadêmicos e empresariais, que ainda a veem como uma grande empresa prestadora de serviços tecnológicos, provenientes do resultado de suas pesquisas.

No processo de cooperação há uma tendência natural em investir na pesquisa aplicada. Entretanto, seria um equívoco imaginar que a Universidade pode se desenvolver apenas numa determinada área. É preciso que ela continue aplicando maciçamente na pesquisa básica, porque é ela quem na realidade vai dar suporte à pesquisa aplicada.

A criação e transferência de conhecimentos ainda é uma função inerente à Universidade, especialmente em países subdesenvolvidos, pela impossibilidade de as empresas criarem seus próprios laboratórios e de construírem um quadro de pesquisadores de alto nível, sobretudo porque é caro e totalmente fora de cogitação em regiões onde há predominância de micro e pequenas empresas, como é o caso dos países latino-americanos.

A cooperação está se transformando num elemento diferenciador dentro das universidades e das empresas. Além de incorporar novos conceitos e práticas de ensino e de pesquisa, vem atendendo aos anseios de uma determinada parcela da comunidade acadêmica e empresarial, constituindo- se como um processo crescente e irreversível.

Entretanto, fica evidente no processo de cooperação, que a Universidade não pode simplesmente fazer parcerias com o setor produtivo porque isso se transformou num modismo nacional e internacional. Para que esse fato venha a se consolidar, trazendo benefícios reais às partes envolvidas, é extremamente importante fazer uma avaliação, para saber se ela se enquadra nos requisitos mínimos para estabelecer uma parceria capaz de contribuir para o desenvolvimento e a inovação tecnológica, que beneficie toda a sociedade. 
Logo, para se implementar um programa de parcerias, a Universidade precisa ter uma série de atributos, pois sem eles se torna inoperante a parceria. Assim, a qualificação de seu pessoal docente com titulação em nível de doutorado passa a ser fundamental. Laboratórios bem equipados, capazes de desenvolver tecnologia de ponta e pesquisa de base, são imprescindíveis no processo, sem os quais não há como imaginar uma contribuição eficaz. A inexistência desses fatores descaracteriza a cooperação e a Universidade desempenhará apenas o papel de prestadora de serviços.

A tendência da relação é aumentar cada vez mais, não apenas pelos fatos assinalados anteriormente, mas, sobretudo, porque as partes envolvidas estão sendo incentivadas a entrar na onda da globalização, interagindo diretamente com ela. Ou seja, se as empresas, a Universidade, e até mesmo o Estado, não se preocuparem com os novos conhecimentos e com o desenvolvimento de tecnologias vão ser atropelados por essa onda.

É importante destacar que o processo somente terá êxito se houver a participação irrestrita dos três segmentos, Universidade, Segmento Empresarial e Governo, conforme preconizado por Sábato e Botana (1968). Nesse sentido, a participação do Estado é fundamental, especialmente no repasse de verbas para a expansão do ensino e da pesquisa; e na difusão dos projetos de incentivos à inovação tecnológica e empresarial, a Universidade, como fiel depositária do conhecimento, deve transformá-lo continuamente e repassá-lo ao segmento empresarial para que este possa transformá-lo e aplicá-lo para uso de toda a sociedade.

Finalmente, entende-se que o processo de transferência de conhecimento científico e tecnológico no continente latino-americano e caribenho não deverá limitar-se às relações internas. Ele deverá transcender as fronteiras dos países e incrementar as relações interinstitucionais com universidades, governos e quiçá com o segmento empresarial, visando ao desenvolvimento da ciência e aumentando a competitividade da região em nível internacional.

\section{REFERÊNCIAS}

COLCIENCIAS. Instituto colombiano para el desarrollo de la ciencia y la tecnología. Disponível em: <http://zulia.colciencias.gov.co/portalcol/index.jsp>. Acesso em: 12 jun. 2008.

CUNHA, N. V. Mecanismos de interação universidade-empresa e seus agentes: o gatekeeper e o agente universitário de interação. Disponível em:

<http://read.adm.ufrgs.br/read09/art/artigo>. Acesso em: 12 mar. 2002.

D’ELORS, J. (Org.). Educação: um tesouro a descobrir - relatório para a UNESCO da Comissão Internacional sobre Educação para o Século XXI. São Paulo, Cortez, 1998.

DIDRIKSON, A. T. La universidad de la innovación: una estrategia de la transformación para la construcción de universidades del futuro. Caracas: IESALC/UNESCO, 2000. (Colección Respuestas).

DRUCKER, P. F. Sociedade pós-capitalista. São Paulo: Pioneira, 1999.

INSTITUTO INTERNACIONAL PARA LA EDUCACIÓN SUPERIOR EM AMÉRICA LATINA Y EL CARIBE. Mapa da educação superior na América Latina e o Caribe.

Disponível em: <www.iesalc.unesco.org.ve>. Acesso em: 06 jun. 2008. 
PLONSKI, G. A. Cooperação universidade-empresa: um desafio gerencial complexo.

Revista de Administração, São Paulo, v. 34, n. 4, p. 5-12, out/dez. 1999.

SABATO, J.; BOTANA, M. La ciência e La tecnologia en el desarrollo futuro de América Latina. Revista de la Integración, Buenos, Aires, n. 2, p. 15-36, 1968.

YUNUS, M. O banqueiro dos pobres. São Paulo: Ática, 2000.

\title{
THE TRANSFER OF SCIENTIFIC AND TECHNOLOGICAL KNOWLEDGE FROM THE UNIVERSITY TO THE BUSINESS SECTOR
}

\begin{abstract}
The article presents an overview of how is structured the process of cooperation between University and business segment in world and proposes guidelines for implementation and strengthening of the process in Latin American universities. The results indicate that knowledge transfer is a routine practice in Asian universities, European and North American, especially from the nineteenth century with the advent of the University of Research. The emergence of a new University, more open, interactive and entrepreneurial in all fronts of action, is evident in the thoughts of authors who compose the text, and consolidates the most academic that the University may only meet its principles and purposes if has the freedom to produce, systematize and make available to society the results of research and educational projects. It proposes the creation of an Agency for Technological Innovation, as an important interface in this new model of university, aligned with the needs of society and trends in a globalized world.
\end{abstract}

Keywords: University, knowledge transfer, agency for innovation.

Data do recebimento do artigo: 24/08/2009

Data do aceite de publicação: 05/11/2009

RAI - Revista de Administração e Inovação, São Paulo, v. 6, n. 3, p. 128-144, set./dez. 2009. 